\title{
Allgrove or 4 " $A$ " syndrome: an autosomal recessive syndrome causing multisystem neurological disease
}

\author{
J Kimber, B N McLean, M Prevett, S R Hammans
}

J Neurol Neurosurg Psychiatry 2003;74:654-657

Allgrove's or "4 A" syndrome is a rare autosomal recessive condition with alacrima, achalasia, autonomic disturbance, and ACTH insensitivity among other features. Recent studies have identified mutations in the AAAS, a candidate gene on chromosome 12 q13 in such patients. Manifestations in adult patients are rarely reported. The syndrome usually presents during the first decade of life with dysphagia or severe (occasionally fatal) hypoglycaemic or hypotensive attacks, related to adrenocortical insufficiency. Onset of adrenal insufficiency or other features may be delayed to adulthood. In contrast with paediatric patients, adult patients with Allgrove's syndrome may present with multisystem neurological disease; the childhood history of achalasia or alacrima may be overlooked. The authors describe two families with two affected siblings and a further unrelated patient with typical clinical features of Allgrove's syndrome, who exhibit signs of multisystem neurological disease including hyperreflexia, muscle wasting, dysarthria, ataxia, optic atrophy, and intellectual impairment. None of the cases have developed adrenal insufficiency but all have progressive neurological disability. Autonomic dysfunction was a significant cause of morbidity in two cases. The three index cases represent the longest described follow up of Allgrove's syndrome into adulthood. It is speculated that they represent a subgroup of patients who follow an often undiagnosed chronic neurological course. Recognition of the syndrome presenting in adult life permits treatment of unrecognised autonomic dysfunction, adrenal insufficiency and dysphagia, and appropriate genetic advice.

A lgrove and colleagues in 1978 first described this syndrome in two pairs of siblings (aged 4-6 years). ${ }^{1}$ All four had achalasia and ACTH insensitivity, three had impaired lacrimation, and one had autonomic dysfunction.

The onset of adrenocortical impairment is usually before puberty, although preservation of cortisol secretion into the third decade has been reported. ${ }^{2}$ The syndrome may thus manifest itself during the first decade of life with severe hypoglycaemic or hypotensive attacks, which may lead to sudden death.

Follow up of the patients originally described by Allgrove, showed all developed variable combinations of sensorimotor polyneuropathy, long tract degeneration, mild dementia, and in one case an akinetic-rigid syndrome by the third decade. ${ }^{3} \mathrm{~A}$ further review of 20 cases aged 2-29 showed additional neurological abnormalities in 17 with onset between 2 and 17 years. These included amyotrophy, dysarthria, ataxia, optic atrophy, intellectual impairment plus autonomic dysfunction. ${ }^{4}$

Previous genetic analysis of eight families with Allgrove's syndrome demonstrated linkage to markers on $12 \mathrm{q}_{13 .{ }^{56}}$ Recent studies in North African and other kindreds with triple
A syndrome has identified mutations in a WD-repeat protein gene, labelled AAAS. ${ }^{78}$

This report describes the clinical features in three adult patients with this disorder, with particular attention to the clinical, neurophysiological, and autonomic abnormalities found in adult patients.

\section{CASE REPORTS \\ Patient 1}

This man aged 40, was born to non-consanguineous parents. At age 5 he was felt to have delayed developmental milestones and subsequently attended a school for learning difficulties. At age 9 he underwent a Heller's cardiomyotomy for achalasia of the cardia and the next year required achilles tendon lengthening surgery. His brother also had achalasia and died of an oesophageal perforation aged 45 . The patient presented aged 34 to neurological services with progressive muscular weakness and gait ataxia. Alacrima, hypostomia, and erectile dysfunction were also noted together with regional hyperhidrosis. Currently he remains ambulant but has developed dysarthria and refractory orthostatic hypotension.

On examination he had dysmorphic facial features with dysarthria and nasal speech. He had dilated pupils with an absent direct light response and poor response to accommodation. Fundoscopy revealed bilateral optic atrophy. Bilateral palatal paresis with an absent gag reflex was noted. His tongue appeared small and spastic with normal filiform papillae. There was global wasting of both arms and legs more marked distally but without fasciculations. Weakness was present in the same distribution. Tendon reflexes were generally brisk but both ankle jerks were absent. Both plantar responses were extensor and he had pes cavus. Limb coordination was relatively preserved but he had marked gait ataxia. Cutaneous sensation including pain perception was normal.

\section{Patient 2}

A woman aged 45, was born of non-consanguineous parents. She was noted to have a nasal voice as a child. She underwent a Heller's cardiomyotomy for achalasia of the cardia aged 24 . She first presented to the neurology service 10 years later with paraesthesiae in the right arm and hand. On examination mild palatal weakness was noted but tendon reflexes were preserved and no firm diagnosis was made. Aged 37 she complained of gait disturbance, posturally induced presyncope, and regional hyperhidrosis and was re-investigated at a neurological centre. Examination findings included reduced direct and consensual pupillary light response with bilateral pallor of the optic discs. Wasting and fasciculation of the tongue with palatal paresis was present. There was distal wasting in the arms and mild pyramidal weakness of the legs. All reflexes were brisk and both plantar responses extensor. She had bilateral pes cavus. Mild limb ataxia was present together with some distal sensory loss in the legs. A marked postural fall in blood pressure was noted. Her diagnosis was made at the age of 43 when she developed frequent blackouts 


\begin{tabular}{|c|c|c|c|}
\hline & Case 1 & Case 2 & Case 3 \\
\hline \multicolumn{4}{|l|}{ Sensory nerve } \\
\hline R sural & Absent & Amp $2.0 \mu \mathrm{V}$, Lat $4.8 \mathrm{~ms}$, C C $29 / \mathrm{ms}$ & Amp $3.7 \mu \mathrm{V}$, Lat $4.0 \mathrm{~ms}, C \vee 30 \mathrm{~ms}^{-1}$ \\
\hline $\mathrm{R}$ digit II & Absent & Amp $2.0 \mu \mathrm{V}$, Lat $2.8 \mathrm{~ms}, C \vee 39 / \mathrm{ms}$ & Amp $9.8 \mu \mathrm{V}$, Lat $2.9 \mathrm{~ms}, C \vee 43 \mathrm{~ms}^{-1}$ \\
\hline$R \operatorname{digit} V$ & Absent & Amp $2.0 \mu \mathrm{V}$, Lat $3.0 \mathrm{~ms}, \mathrm{CV} 33 / \mathrm{ms}$ & Amp $4.6 \mu \mathrm{V}$, Lat $3.4 \mathrm{~ms}, C \vee 35 \mathrm{~ms}^{-1}$ \\
\hline$R$ median $C A P$ & Amp $7.7 \mu \mathrm{V}$, Lat $4.0 \mathrm{~ms}, C \vee 68 / \mathrm{ms}$ & - & - \\
\hline R ulnar CAP & Amp $7.5 \mu \mathrm{V}$, Lat $4.1 \mathrm{~ms}, C \vee 68 / \mathrm{ms}$ & - & - \\
\hline $\mathrm{R}$ radial & Amp $6.5 \mu \mathrm{V}$, Lat $2.3 \mathrm{~ms}$, C V $49 / \mathrm{ms}$ & - & 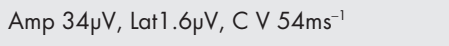 \\
\hline \multicolumn{4}{|l|}{ Motor nerve } \\
\hline R tibial & Absent & Amp $5.0 \mathrm{mV}$, Lat $5.4 \mathrm{~ms}, C V 40 / \mathrm{ms}$ & _- \\
\hline R peroneal - EDB & Absent & Amp $3.5 \mathrm{mV}$, Lat $5.0 \mathrm{~ms}$, C V $39 / \mathrm{ms}$ & Amp $7.4 \mathrm{mV}$, Lat $4.7 \mathrm{~ms}, C \vee 43 \mathrm{~ms}^{-1}$ \\
\hline R ulnar & Amp 0.2, Lat $3.7 \mathrm{~ms}, C V 40 / \mathrm{ms}$ & Amp $4.0 \mathrm{mV}$, Lat $3.8 \mathrm{~ms}$, C V $47 / \mathrm{ms}$ & Amp $6.7 \mathrm{mV}$, Lat $3.1 \mathrm{~ms}, C \vee 53 \mathrm{~ms}^{-1}$ \\
\hline $\mathrm{R}$ median & Absent & Amp 9.omV, Lat $4.6 \mathrm{~ms}, C \vee 43 \mathrm{~ms}^{-1}$ & Amp $7.6 \mathrm{mV}$, Lat $4.7 \mathrm{~ms}, C \vee 49 \mathrm{~ms}^{-1}$ \\
\hline \multicolumn{4}{|l|}{ EMG } \\
\hline R EDC & $\begin{array}{l}\text { Nil spontaneous, Large polyphasic AP, } \downarrow \\
\text { interference }\end{array}$ & - & $\begin{array}{l}\text { Nil spontaneous, } \uparrow \text { duration polyphasic AP, } \\
\downarrow \text { interference }\end{array}$ \\
\hline R Quadriceps & - & $\begin{array}{l}\text { Fasiculations, Large polyphasic AP, } \downarrow \\
\text { interference }\end{array}$ & $\begin{array}{l}\text { Nil spontaneous, } \uparrow \text { duration polyphasic AP, } \\
\downarrow \text { interference }\end{array}$ \\
\hline R Biceps & $\begin{array}{l}\text { Fibrillations; Large polyphasic AP, } \downarrow \\
\text { interference }\end{array}$ & $\begin{array}{l}+ \text { ve sharp waves, Large polyphasic AP, } \\
\downarrow \text { interference }\end{array}$ & - \\
\hline R Triceps & - & $\begin{array}{l}\text { Fasiculations, Large polyphasic AP, } \downarrow \\
\text { interference }\end{array}$ & - \\
\hline R Tib Ant & $\begin{array}{l}\text { Fibrillations; Large polyphasic AP, } \downarrow \\
\text { interference }\end{array}$ & $\begin{array}{l}\text { Nil spontaneous, Large polyphasic AP, } \downarrow \\
\text { interference }\end{array}$ & $\begin{array}{l}\text { Nil spontaneous, } \uparrow \text { duration polyphasic AP, } \\
\downarrow \text { interference }\end{array}$ \\
\hline R APB & - & $\begin{array}{l}\text { Nil spontaneous, Large polyphasic AP, } \downarrow \\
\text { interference }\end{array}$ & - \\
\hline \multicolumn{4}{|l|}{ Evoked potentials } \\
\hline VEP & Bilateral delay & Bilateral delay & Normal \\
\hline BSAEP & Normal & Normal & Normal \\
\hline SSEP & Bilateral delay & Bilateral delay & Bilateral delay \\
\hline $\begin{array}{l}\text { Skin sympathetic } \\
\text { response }\end{array}$ & Absent in all four limbs & Absent in all four limbs & - \\
\hline
\end{tabular}

Amp, amplitude; Lat, disatal latency; CV, conduction velocity; CAP, compound action potentail; AP, action potential; Tib Ant, tibilais anterior; EDC, extensor digitorum communis; APB, abductor pollicis brevis; VEP, visual evoked potential; BSEAP, brain stem auditory evoked potential; SSEP, somatosensory evoked potentials from the lower limb.

and dysphagia. Currently she requires PEG feeding and is treated with midodrine for postural hypotension. Her sister died of carcinoma of the ovary in her fifth decade and had milder but qualitatively similar neurological symptoms. Both siblings also exhibited features of gonadotrophic dysfunction; delayed menarche, early menopause, and reduced fertility.

\section{Patient 3}

This man aged 60 years, was born to non-consanguineous parents. At age 12 he was noted to have a scoliosis. By the age of 20 his gait was unsteady and was aware of reduced temperature sensation in his feet. Aged 28 he developed dysphagia and subsequently underwent a Heller's procedure for achalasia of the cardia. Aged 60 he presented to the neurology service with frequent blackouts related to sudden postural change. Erectile dysfunction and regional hyperhidrosis were also noted. His walking had deteriorated and had limited mobility with one stick. On examination there was right sided partial ptosis together with meiosis. Pursuit eye movements were fragmented. Speech was normal. Wasting of the interossei was present bilaterally, although limb power was relatively preserved. Reflexes were brisk and the left plantar response was extensor. Reduced sensation was evident in the legs to the mid calf. Lower limb and gait ataxia were present.

\section{INVESTIGATIONS}

In each case biochemical, haematological, and autoantibody screening proved negative. Plasma hexos aminidase A and B, arylsulphatase and very long chain fatty acids were within normal limits. No metachromatic granules were seen in urine samples. In cases 1 and 2, Schirmer's test confirmed bilateral alacrima and computed tomography of the orbits showed reduced lacrimal gland tissue. Electrophysiology, cardiovascular autonomic and adrenal function test results are shown in tables IA and B. MRI of the brain and cervical spine was normal except for mild cerebellar atrophy (case 1) and non-specific ischaemic changes in the cerebral white matter (case 3 ).

Sural nerve biopsy in case 1 revealed changes consistent with axonal degeneration with marked loss of myelinated axons and some unmyelinated fibres. In case 2 a severe axonal neuropathy with secondary demyelination but normal fibre density was observed. Little regeneration and no amyloid was seen. Quadriceps muscle biopsy in cases 1 and 2 showed neurogenic atrophy.

\section{DISCUSSION}

In all our cases achalasia preceded the development of progressive neurological disease-typically a combination of sensorimotor polyneuropathy, long tract degeneration, optic neuropathy, and cerebellar features together with impaired parasympathetic and sympathetic autonomic function.

Palatal paresis was a feature in two of our cases and is reported by other authors. ${ }^{249}{ }^{10}$ It is an uncommon finding in neuropathy and may represent central neuronal degeneration.

There are several reports in the literature of severe neuropathy, ${ }^{6-12-16}$ ataxia, ${ }^{17}$ or alacrima ${ }^{18}$ with achalasia and we speculate that these too are forms of Allgrove's syndrome. The syndrome seems least likely to be recognised if presenting with neurological features in adult life.

Intellectual impairment was suggested by the clinical history in case one, although formal neuropsychometry was not performed. Cognitive problems have been recognised in some paediatric patients with Allgrove's syndrome. ${ }^{2411}$ 
Table 1B Cardiovascular autonomic and adrenal function tests

\begin{tabular}{|c|c|c|c|}
\hline & Case 1 & Case 2 & Case 3 \\
\hline \multicolumn{4}{|l|}{ Adrenal function } \\
\hline Basal cortisol + synacthen $250 \mathrm{IU}$ & $513 \mathrm{nmol} / \mathrm{l}$ & $215 \mathrm{nmol} / \mathrm{l}$ & $302 \mathrm{nmol} / \mathrm{l}$ \\
\hline $30 \mathrm{~min}$ & $926 \mathrm{nmol} / \mathrm{l}$ & $456 \mathrm{nmol} / \mathrm{l}$ & $554 \mathrm{nmol} / \mathrm{l}$ \\
\hline $60 \mathrm{~min}$ & $1260 \mathrm{nmol} / \mathrm{l}$ & $980 \mathrm{nmol} / \mathrm{l}$ & $890 \mathrm{nmol} / \mathrm{l}$ \\
\hline Basal ACTH & $26.7 \mathrm{ng} / \mathrm{l}$ & - & - \\
\hline Recumbent aldosterone & 77.0ng/l & $10.9 \mathrm{ng} / \mathrm{I}^{*}$ & - \\
\hline Recumbent renin & $20 \mathrm{mU} / \mathrm{l}$ & $37.0 \mathrm{mU} / \mathrm{I}$ & - \\
\hline \multicolumn{4}{|l|}{ Postural challenge } \\
\hline Lying/standing BP & $108 / 70-89 / 56^{*}$ & $145 / 95-104 / 67^{*}$ & $148 / 85-162 / 89$ \\
\hline $30: 15$ ratio & $1.0^{*}$ & $1.0^{*}$ & - \\
\hline \multicolumn{4}{|l|}{ HR response to respiratory stimulii } \\
\hline Deep breathing & $4^{*}$ & $2^{*}$ & $4^{*}$ \\
\hline \multicolumn{4}{|l|}{ Pressor tests } \\
\hline \multicolumn{4}{|l|}{ Cutaneous cold } \\
\hline BP & $111 / 53-112 / 69$ & $122 / 85-120 / 78^{*}$ & $138 / 84-165 / 88$ \\
\hline HR & $75-81$ & $78-88$ & $70-78$ \\
\hline \multicolumn{4}{|l|}{ Isometric exercise } \\
\hline $\mathrm{BP}$ & - & $130 / 85-122 / 75^{*}$ & $137 / 85-136 / 88^{*}$ \\
\hline $\mathrm{HR}$ & - & $77-80$ & $70-68$ \\
\hline \multicolumn{4}{|l|}{ Mental arithmetic } \\
\hline BP & $115 / 80-126 / 71$ & $127 / 89-120 / 74^{*}$ & $137 / 83-147 / 93$ \\
\hline $\mathrm{HR}$ & $76-80$ & $77-84$ & $72-70$ \\
\hline
\end{tabular}

BP, blood pressure; HR, heart rate; $\mathrm{ACTH}$, adrenocortical trophic hormone. *Denotes an abnormal response.

Our cases are remarkable in that adrenocortical function was preserved into the fifth decade confirming that this feature of Allgrove's syndrome may be absent or occur later in the course of the disease. ${ }^{19}$ In one patient aldosterone responses alone appeared impaired. This has been reported in younger patients. ${ }^{30}$

Autonomic dysfunction contributed significantly to morbidity in two of our cases and seemed to involve cardiac parasympathetic, cholinergic sympathetic (sudomotor), cranial, and pelvic parasympathetic (pupillomotor, lacrimotor, erectile function). Previous authors have suggested dysfunction is limited to cholinergic neurones in Allgrove's syndrome. ${ }^{921}$ Two of our cases also had impaired sympathetic vasoconstrictor (noradrenergic) function, although the possibility of an additional central autonomic defect cannot be ruled out.

Sural nerve biopsies in two patients showed changes consistent with axonal degeneration and loss of both myelinated and unmyelinated fibres with no amyloid deposition. The aetiology of the neuropathy in Allgrove's syndrome is obscure. Previous authors have suggested it may result from a defect of ACTH receptors on neurones/glia with secondary demyelination, ${ }^{14}$ but further work has not provided support for this theory.

In two of our cases a second sibling was affected by a similar multisystem neurological illness, consistent with autosomal recessive inheritance. Allgrove syndrome has shown linkage to chromosome 12q13 with no indication of genetic heterogeneity. ${ }^{5}$ Recent studies in North African and other kindreds with triple A syndrome has identified mutations in a WD-repeat protein gene, labelled AAAS, although no clinicogenetic correlation was demonstrated. ${ }^{78}$ Genetic analysis of the AAAS gene in collaboration with Dr Huebner's groups in Dresden revealed a compound heterozygous AAAS mutation consisting of two mutations: a G>A transition in exon 6 resulting in a change of the arginine at amino acid position 155 into histidine (Arg 155His or R155H; missense mutation) on one allele, and a G>A transition in exon 10 resulting in a change of tryptophane at amino acid position 324 into a stop codon (Trp324stop or W324X; nonsense mutation).

We suspect that Allgrove's syndrome may be an underdiagnosed cause of multisystem neurological disease. Achalasia and alacrima are valuable non-neurological clues to the diagnosis. We speculate that there maybe a subgroup of patients who follow a chronic neurological course after a less severe paediatric presentation. Recognition of the syndrome presenting in adult life permits treatment of unrecognised autonomic dysfunction, adrenal insufficiency, and dysphagia. Further clinical and genetic analysis will define the phenotype more precisely and permit identification of patients with incomplete manifestations of the syndrome.

\section{ACKNOWLEDGEMENT}

The authors would like to gratefully acknowledge the collaboration of Dr Angela Huebner Medizinische Fakultät Carl Gustav Carus, Technische Universität Dresden for the analysis of the AAAS gene mutations in our patients.

\section{Authors' affiliations}

J Kimber, M Prevett, S R Hammans, Wessex Neurological Centre,

Southampton General Hospital, Southampton, UK

B N McLean, Royal Cornwall Hospital, Treliske, Cornwall, UK

Competing interests: none declared

Correspondence to: Dr J Kimber, Department of Neurology, Atkinson Morley's Hospital, Copse Hill, Wimbledon, London SW2O ONE, UK; jeff.kimber@doctors.org.uk

Received 1 June 2001

In revised form 23 October 2001

Accepted 13 December 2001

\section{REFERENCES}

1 Allgrove J, Clayden G, Grant D, et al. Familial glucocorticoid deficiency with achalasia of the cardia and deficient tear production. Lancet 1978;i:1284-6.

2 Moore $\mathbf{P}$, Couch R, Perry $Y$, et al. Allgrove syndrome: an autosomal recessive syndrome of $\mathrm{ACTH}$ insensitivity, achalasia and alacrima. Clin Endoc (Oxf) 1991;34:107-14.

3 Grant D, Dunger D, Smith I, et al. Familial glucocorticoid deficiency with achalsia of the cardia associated with a mixed neuropathy, long tract degeneration and mild dementia. Eur J Pediatr 1992;151:85-89.

4 Grant D, Barnes N, Dumic $M$, et al. Neurological and adrenal dysfunction in the adrenal insufficiency/alacrima/achalasia syndrome. Arch Dis Child 1993;68:779-82. 
5 Weber A, Wienker $T$, Jung $M$, et al. Linkage of the gene for the "triple $A^{\prime \prime}$ syndrome to chromosome 12 q13 near the type ll keratin gene cluster. Hum Mol Genet 1996:5:2061-6.

6 Stratakis C, Lin J, Pras E, et al. Segregation of Allgrove syndrome in Puerto Rican kindreds with chromocome 12q13 polymorphic markers. Proc Assoc Am Phys 1997; 109:478-82.

7 Handschug K, Sperling S, Yoon SJ, et al.Triple A syndrome is caused by mutations in AAAS, a new WD-repeat protein gene. Hum Mol Genet 2001;10:283-90.

8 Tullio-Pelet A, Salomon R, Hadj-Rabia S, et al. Mutant WD-repeat protein in triple-A syndrome. Nat Genet 2000;26:332-5.

9 Chu M, Berlin D, Axelrod F. Allgrove syndrome; documenting cholinergic dysfunction by autonomic function tests. J Paediatr 1996; 129:156-9.

10 Bentes C, Santos-Bento M, de Sa J, et al. Allgrove syndrome in adulthood. Muscle Nerve 2001;24:292-6.

11 Ehrich E, Aranoff G, Johnson W. Familial achalasia associated with adrenocortical insufficiency, alacrima and neurological abnormalities. $J$ Med Genet 1987;26:637-44.

12 Longstreth G, Walker F. Mega-oesophagus and hereditary nervous system degeneration. Clin Gastroenterol 1994;19:125-7.

13 Lisker R, Garcia-Ramos G, de la Rosa-Laris C, et al. Peripheral autonomic neuropathy associated with autonomic dysfunction in two sisters-a new hereditary syndrome? Am J Genet 1981;9:255-9.
14 Stuckey B, Mastalgia F, Reed W, et al. Glucocorticoid deficency, achalasia, alacrima with autonomic and motor neuropathy. Ann Intern Med 1987; 106:62-4

15 Tsao C, Romshe C, LO W, et al. Familial adrenal insufficency, achalasia, alacrima, peripheral neuropathy, microcephaly: normal plasma very long chain fatty acids and normal muscle mitochondrial plasma very long chain fatty acids and normal muscle mitocho
respiratory chain enzymes. J Child Neurol 1994;9:135-8.

16 Deumic M, Radich A, Jusic A, et al. Selective ACTH insensitivity associated with autonomic nervous system abnormalities and sensorimotor polyneuropathy. Eur J Pediatr 1987; 146:592-4.

17 Murphy M, Gardner-Medwin D, Eastham E. Achalasia of the cardia associated with hereditary cerebellar ataxia. Am J Gastroenterol 1989;84:1329-30.

18 Verma S, Brown R, Dakkak M, et al. Association of adult achalasia and alacrima. Dig Dis Sci 1999:44:876-8.

19 El-Rayyes K, Hegab S, Beisisso M. A syndrome of alacrima, achalasia, and neurological abnormalities without adrenocortical insufficiency. J Pediatr Ophthalmol Strabismus 1991;28:35-7.

20 Pombo M, Devesa J, Taborda A, et al. Glucocorticoid deficiency with achalasia of the cardia and lack of lacrimation. Clin Endocrinol 1985;23:237-43

21 Lanes R, Plotnick L, Bynum T, et al. Glucocorticoid and artial mineralocorticoid deficiency associated with achalasia. J Clin Endoc Metab 1980;50:268-70. 